\title{
Personagens ao encontro de um autor: * o ator-diretor de uma instituição científica no Brasil do século XX
}

\author{
Claudia Regina Rodrigues Ribeiro Teixeira** \\ André Luis Gemal*** \\ André de Faria Pereira Neto $* * *$
}

\section{Prólogo}

Desde 1990, a vigilância sanitária é definida pela Lei Orgânica da Saúde como "um conjunto de ações capaz de eliminar, diminuir, ou prevenir riscos à saúde e de intervir nos problemas sanitários decorrentes do meio ambiente, da produção e circulação de bens e da prestação de serviços de interesse da saúde" (Brasil, 1990).

Fruto da incorporação e transferência do Laboratório Central de Controle de Drogas, Medicamentos e Alimentos (LCCDMA), em 1978, para

* Seis personagens à procura de um autor: obra de 1921 de Luigi Pirandello (1867-1936), dramaturgo siciliano, que propõe uma reflexão sobre a criação artística e sobre o poder da arte. A analogia do título do artigo reside nos binômios criação-poder e personagens-autor. Nossos agradecimentos à Coordenação de Aperfeiçoamento de Pessoal de Nível Superior (Capes) pelo apoio acadêmico, dado pelo Programa de Doutorado com Estágio no Exterior (2008-2009), e a Monsieur Jean-Pierre Goubert, professor da École des Hautes Études en Sciences Sociales (Paris, França) pela atenciosa leitura e valorosos comentários.

** Química. Instituto Nacional de Controle de Qualidade em Saúde da Fundação Oswaldo Cruz (Fiocruz).

*** Farmacêutico-Bioquímico. Departamento de Química Orgânica, Instituto de Química, Universidade Federal do Rio de Janeiro (UFRJ).

**** Historiador. Casa de Oswaldo Cruz, Fundação Oswaldo Cruz (Fiocruz). 
a Fundação Oswaldo Cruz (Fiocruz), o Instituto Nacional de Controle de Qualidade em Saúde (INCQS) se configura como a instância laboratorial, de caráter nacional, que atua em áreas de ensino, de pesquisa e de tecnologias de laboratório relativas ao controle da qualidade de insumos, produtos, ambientes e serviços sujeitos à ação da Vigilância Sanitária, sendo, portanto, o órgão técnico-científico do Ministério da Saúde capaz de atender às suas demandas políticas naquele âmbito.

Tendo como missão a contribuição para a promoção e recuperação da saúde e prevenção de doenças, atuando como referência nacional para as questões científicas e tecnológicas relativas ao controle da qualidade de produtos, ambientes e serviços vinculados à Vigilância Sanitária, o INCQS desenvolve suas atividades em estreita cooperação com a Agência Nacional de Vigilância Sanitária (Anvisa), com secretarias estaduais e municipais de saúde, entre outros parceiros.

É nesse palco que se desenrola a presente trama.

\section{O levantar da cortina}

Durante as duas últimas semanas daquele longínquo agosto, o entra e sai dos paletós pretos dos carrancudos agentes do Serviço Nacional de Informações pelas dependências do prédio, cujas marcas da construção recém-acabada eram bem visíveis, contrastou com a alvura dos jalecos dos químicos, farmacêuticos e biólogos recém-contratados.

Extensos formulários de investigação pessoal e profissional tiveram que ser previamente preenchidos e aprovados, a circulação pelos corredores foi rigorosamente delimitada e os crachás de identificação emitidos pela Polícia Federal deveriam ser portados de forma bem visível e seu uso seria terminantemente obrigatório.

Os tempos eram assim...

No final daquela manhã nublada de final de inverno carioca, através dos vidros das janelas hermeticamente fechadas de nossos "bunkers" laboratoriais, estupefatos, irrequietos, apreensivos e esperançosos, vimos chegar ao estacionamento vazio o longo desfile de Opalas pretos.

Portando trajes civis e tendo ao seu lado o ministro de Estado da Saúde e o presidente da Fiocruz, o general João Batista de Oliveira Figueiredo, último presidente militar da República Federativa do Brasil, desceu do carro e 
descerrou a placa de bronze incrustada no portentoso bloco de granito. Sem muita pompa, mas com toda circunstância e austeridade, cortou a fita auriverde e adentrou o prédio. Era sexta-feira, dia 4 de setembro de 1981.

Estava inaugurado o Instituto Nacional de Controle de Qualidade em Saúde.

O que teria acontecido até chegarmos àquele momento foi uma pergunta que durante muitos anos ecoou na mente dos que ali estavam presenciando o episódio. Optamos por tentar respondê-la a partir dos depoimentos orais do primeiro dirigente da instituição - Eduardo Motta Alves Peixoto - ainda que fosse possível fazê-lo também por meio de documentos escritos (atas, memorandos, ofícios, projetos, relatórios, convênios, cartas), ou de imagens daquele período. Não obstante, a escolha recaiu sobre esta forma de registro: o da memória do primeiro dirigente da instituição.

Para tanto, valemo-nos da metodologia da história oral, que tem sido utilizada por pesquisadores em diversas áreas de abrangência, a partir da elaboração e utilização de entrevistas gravadas.

No presente trabalho, as entrevistas foram antecedidas pela elaboração de um roteiro de perguntas, baseadas no curriculum vitae de Eduardo Peixoto e no estudo preliminar do tema no qual a instituição está inserida, qual seja a vigilância sanitária.

Após o registro em fitas magnéticas, as entrevistas foram transcritas, editadas e conferidas e, a partir daí, foram utilizadas neste trabalho, o qual se insere em uma ampla pesquisa sobre o instituto.

\section{Cenário}

O Instituto Nacional de Controle de Qualidade em Saúde (INCQS) se integra no complexo sistema de vigilância sanitária brasileiro. No Brasil, até a metade do século $\mathrm{XX}$, a vigilância sanitária era vista como uma instância do poder público que exercia exclusivamente uma função coercitiva e punitiva sobre o cidadão (Costa, 1999).

Entretanto, essa visão foi paulatinamente sendo alterada, sobretudo a partir da segunda metade dos anos 1970, quando se esboçaram os primeiros traços de reformulação do pensamento e estrutura na área da saúde, posteriormente denominada como "Movimento da Reforma Sanitária". Atualmente, a vigilância sanitária tem suas atividades relativas voltadas para o 
registro, normatização, propaganda e controle de qualidade de alimentos, medicamentos, saneantes, cosméticos e artigos de saúde, para as inspeções de serviços de saúde, pesquisas clínicas e para as atividades de portos, aeroportos e fronteiras. Para que essas competências fossem efetivamente realizadas foram sendo construídas, em diferentes realidades regionais, instituições com a finalidade precípua de responder pela vigilância sanitária.

Assim, a história institucional da vigilância sanitária no Brasil esteve intimamente associada ao processo de organização da saúde pública. As competências da vigilância sanitária estiveram vinculadas ao Ministério da Saúde desde sua criação em 1953 (Brasil, 1953). Ainda nos primeiros meses do ano seguinte, foi criado o primeiro laboratório voltado especificamente para o controle de qualidade de produtos: Laboratório Central de Controle de Drogas e Medicamentos (LCCDM). Cabe ressaltar que no momento de sua criação, a conjuntura político-econômica do país experimentava considerável pressão militar, apoiada pela classe empresarial e pelo governo norteamericano (Dreifus, 2006). Assim, a instituição que tinha como finalidade "examinar e a analisar drogas, plantas medicinais, especialidades farmacêuticas, anti-sépticos, desinfetantes, produtos biológicos e químicos e quaisquer outras substâncias que fossem do âmbito da saúde pública”, também deveria "favorecer o desenvolvimento técnico-científico da indústria farmacêutica do país, estabelecendo, mantendo e fornecendo normas e padrões necessários a essa indústria e à de produtos biológicos", além de "propor a cassação da licença de produtos cuja análise sistemática provasse a má-fé do seu fabricante, bem como a modificação das fórmulas em que os conhecimentos científicos atualizados viessem provar inatividade ou dano para a saúde pública” (Brasil, 1954).

Considerando que o sangue e os cosméticos podem ser incluídos na condição de produtos biológicos e químicos, a única área que não se encontrava contemplada naquele momento na determinação legal de criação e atribuições do LCCDM era a dos produtos alimentícios. Estes só foram incorporados em 1961, com a edição do Código Nacional de Saúde (Brasil, 1961). Nesta oportunidade, o laboratório criado em 1954 passou a ser denominado como Laboratório Central de Controle de Drogas, Medicamentos e Alimentos (LCCDMA), ou seja, esta nova instituição incluiu a expressão alimento à sua denominação oficial. Portanto, é razoável supor que, embora a contribuição do setor alimentício no crescimento total da economia do país fosse de apenas de 16\% (Birchal, 2004), a expansão tecnológica de algumas 
importantes indústrias nacionais e internacionais do setor teria influenciado a referida inclusão nas atribuições daquele laboratório.

Em 1964, três anos após a edição do referido código, a conjuntura política brasileira se alterou profundamente com a deposição do presidente da República, por meio de um golpe militar, resultante, dentre outras razões políticas que fogem ao escopo do presente trabalho, também da ativa articulação entre militares e empresários de importantes setores do cenário econômico brasileiro (Dreifus, 2006), aí incluídas as indústrias de alimentos e medicamentos.

Com essa mudança radical na política brasileira, o final dos anos 1960 e a década de 1970 foram marcados pela edição de inúmeras leis, decretos-leis e decretos que visavam ao exercício do poder público sobre o controle de qualidade de produtos afetos à saúde, como alimentos, medicamentos, saneantes e cosméticos, para atender às demandas do projeto político-econômico então vigente.

No entanto, em 1976, o Ministério da Saúde teve sua estrutura organizacional reformulada e as ações inerentes à vigilância sanitária, até então vinculadas ao Serviço Nacional de Fiscalização de Medicina e Farmácia, receberam o status de secretaria ministerial, indicativo claro do reconhecimento da importância e da relevância do tema dentro da política governamental, sendo criada a Secretaria Nacional de Vigilância Sanitária (SNVS) (Brasil, 1976).

Junto com ela, a Secretaria Nacional de Ações Básicas em Saúde (SNABS), a Secretaria Nacional de Programas Especiais em Saúde (SNPES) e a Superintendência de Campanhas de Saúde (Sucam) compunham o quadro de órgãos da administração de atividades específicas do Ministério da Saúde. Com essa medida, dava-se à nova secretaria a competência da promoção, elaboração, controle da aplicação e fiscalização de normas e padrões de interesse sanitário relativos a portos, aeroportos, fronteiras, produtos médicofarmacêuticos, bebidas, alimentos e outros produtos ou bens de interesse à saúde. No regimento interno da SNVS estavam estabelecidas a sua organização, as competências das divisões que a integravam e as atribuições de seus dirigentes. Em outro instrumento legal estava estabelecido que o LCCDMA permaneceria subordinado àquela secretaria, estando prevista, no entanto, sua transferência para a Fiocruz.

Portanto, tendo sido criado um órgão com atribuições específicas de vigilância sanitária, é perfeitamente compreensível que o laboratório (LCCDMA) que respondia pelo controle dos produtos afetos àquela área 
permanecesse subordinado à nova secretaria, porém, resta saber por que então ficou prevista sua transferência para a Fiocruz? Que interesses envolveram essa mudança?

Para Vinicius da Fonseca, economista oriundo da Secretaria de Planejamento, órgão da Presidência da Republica, de relevante papel na condução política e econômica do país durante o governo Geisel (1974-1979), que exerceu a presidência da Fiocruz entre 1975 e 1979, o LCCDMA "praticamente não existia” e era "inimaginável controlar medicamentos numa época em que as multinacionais estavam entrando no Brasil" (Hamilton; Azevedo, 2001, p. 257). Apesar de discordar da medida, acabou tendo que acatar a decisão do então ministro da Saúde, o médico Paulo de Almeida Machado (1913-1991), que exerceu o cargo entre 1974 e 1979, afirmando porém que viabilizou apenas a concepção do projeto físico para a instalação da unidade na Fiocruz.

Concomitantemente, o Plano Nacional de Controle da Poliomielite, elaborado em 1971, apresentava inúmeras falhas, tendo sido notificados surtos da doença em quase todos os estados brasileiros entre 1975 e 1979 (Schatzmayer et al., 2002). Segundo João Batista Risi Jr. (2003, p. 777), médico, secretário nacional de Ações Básicas de Saúde, no Ministério da Saúde, na gestão de Waldir Arcoverde, entre 1980 e 1985, "em 1979 a situação da poliomielite era nitidamente grave, em função de baixas coberturas vacinais”.

A inexistência de um órgão de controle adequado às exigências econômicas e sociais do país, portanto, parecia ser a tônica daquele momento, tanto na área de produtos como alimentos e medicamentos quanto na área das vacinas. A resolução desse problema exigiria recursos de toda ordem que, pelo sistema administrativo então vigente, seriam mais facilmente alocados em fundações. Estariam aí os motivos mais do que razoáveis para a transferência?

Antes de responder à questão, cabe dizer que a transferência se efetivou legalmente pela edição de portaria ministerial, promulgada em outubro de 1978 (Brasil, 1978). Ali estava estabelecido que a Fiocruz articular-se-ia com a SNVS, de modo a assumir integralmente a responsabilidade pela gestão técnica, administrativa, orçamentária e financeira do LCCDMA.

Concretamente, a transferência se deu com a inauguração, no dia 4 de setembro de 1981, da nova unidade técnica na Fiocruz, que foi denominada como Instituto Nacional de Controle de Qualidade em Saúde, com as atribuiçõos outrora exercidas pelo LCCDMA.

Com a cortina já levantada e com o cenário montado, passemos ao personagem. 


\section{personagem no palco}

Eduardo Motta Alves Peixoto foi nomeado pelo ministro da Saúde, o médico Waldyr Mendes Arcoverde (1979-1985), como primeiro dirigente do novo instituto. Que caminhos pessoais e profissionais percorreu até chegar a ocupar o cargo de diretor? Que tipo de modelo de gestão pretendia adotar ao assumir a direção? Quais eram seus ideais para a instituição e de que forma estava mais ou menos alinhado às diretrizes da política do Ministério da Saúde naquele momento? Essas foram as questões que nortearam as entrevistas.

Para tanto, fez-se necessário conhecer um pouco mais sobre a vida do personagem, desde seus primeiros anos, e também como concebia a gestão empresarial e pública.

\section{A formação do personagem}

Eduardo Motta Alves Peixoto, nascido em Salvador, em 1939, filho de pais que eram médico e professora primária, declara no início da entrevista que "a família era, por parte do meu pai, uma família aristocrata do Recôncavo", e que a cidade onde seu pai exercia a medicina e era proprietário de uma farmácia - Maragojipe - "era uma das mais progressistas, no início do século, da Bahia”. A família numerosa (sete filhos), os deslocamentos paternos entre a capital e o interior por força do exercício de sua profissão, os falecimentos da irmã mais nova e da mãe, a moradia, já em Salvador, em "uma região [bairro de Nazaré], digamos, politicamente agitada”, em que o relacionamento familiar com pessoas que se tornariam importantes figuras da política nacional era habitual, caracterizaram a vida social ao longo da sua infância:

Waldir Pires [político baiano] era um vizinho. Irmãos meus frequentavam a casa dele e tudo. Quer dizer, eram famílias que conviviam bastante. E uma mesma coisa, e uma parte também com a de Antônio Carlos Magalhães [político baiano], que também morava na mesma região. Então naquela região tinha políticos de direta, políticos de esquerda. Tinha de tudo.

Vê-se, portanto, que no ambiente familiar circulavam igualmente futuros políticos da esquerda e da direita brasileira, não havendo uma clara demonstração das tendências políticas da família. 
A formação escolar, à parte os primeiros anos básicos, foi feita em um colégio da congregação dos padres maristas. Do período em que Eduardo Peixoto tinha entre 11 e 12 anos de idade, foi possível perceber três elementos que podem ter contribuído para a iniciação do entrevistado no campo científico, que seriam o acesso à leitura em sua casa, a farmácia pertencente ao seu pai, onde eram manipulados medicamentos, e a busca de interação com os colegas de turma.

Segundo ele, as atividades experimentais no campo da química recebiam o apoio paterno e dos educadores do Colégio Marista de Salvador e acabaram por incentivá-lo na criação de um clube, instalado no laboratório farmacêutico de seu pai, onde eram feitos seminários e palestras apresentados por professores locais e convidados: "A gente tinha condições de fazer experiências que nenhuma Universidade na Bahia tinha."

Esses fatos, além da correspondência mantida entre ele e alguns pesquisadores internacionais da área da química, como Linus Carl Pauling (19011994), químico quântico e bioquímico, Prêmio Nobel de Química em 1954 e Prêmio Nobel da Paz, em 1962; Gilbert Newton Lewis (1875-1946), químico; Adolf Otto Reinhold Windaus (1876-1959), químico e Prêmio Nobel de Química em 1928; e com os fundadores do Instituto de Química da Universidade de São Paulo, Heinrich Hauptmann (1905-1960) e Heinrich Rheinboldt (1891-1955), parecem ter sido preponderantes para que Eduardo Peixoto optasse por seguir a carreira de químico, e não a de farmacêutico, apesar de todo o seu envolvimento com a manipulação de substâncias químicas para a formulação de medicamentos na farmácia de seu pai. Ao se inscrever em um concurso de ciências voltado para jovens estudantes em São Paulo e ser premiado, Eduardo Peixoto mudou-se para aquela cidade, onde iniciou e concluiu seus estudos universitários, inicialmente com o suporte financeiro de seu pai e de seu irmão.

\section{Cenas do personagem na Paulicéia e em New York City. Os bastidores da USP}

Na Faculdade de Filosofia, Ciências e Letras da Universidade de São Paulo (USP), entre 1957 e 1961, Eduardo Peixoto foi reafirmando sua característica de pesquisador delineada na adolescência. De suas declarações podemos perceber a dedicação às novas técnicas no campo da química e seu reconhecimento 
por parte de seus professores, posto que, mesmo antes de concluir seu curso de graduação, já desempenhava suas atividades como profissional.

Em 1957, aqui [em São Paulo] na universidade, ninguém fazia cromatografia. A química começou a ter cromatografia como pesquisa em 1960, mais ou menos. Aí antes de terminar a faculdade eu comecei a trabalhar como consultor para uma indústria.

Nos anos seguintes, a carreira de químico foi se consolidando pelas atividades em empresas privadas de vários setores no ramo da química, exercendo cargos de pesquisador e de chefia.

Eu era chefe da produção... Fui chefe de vendas uma parte e era chefe de tudo onde eu entrava. Passei a ficar só com os diretores e com os donos. Mas eu dirigia a produção toda de poliéster [na Ucebel Produtos Químicos S. A.] e tudo. E aí depois eu saí de lá e fui para uma fábrica que trabalhava com diamantes [Diamantes "Roder" S. A.]. E aí eu montei todo o centro de pesquisa dele, a produção, eu era chefe da produção, controle de qualidade, testes, tudo. Aí a fábrica floresceu.

Nesse ponto, Eduardo Peixoto, jovem, e pelo seu relato, já profissionalmente bem sucedido, faz menção à instabilidade econômica e política do país naquele momento - início dos anos 1960 - que teria motivado o seu "desencanto" com as atividades que desempenhava na indústria química. Daí a decisão de aceitar o convite de dar continuidade a seus estudos, em nível de doutoramento e pós-doutoramento, em universidades americanas, como bolsista da Rockefeller Foundation, durante cinco anos (1964-1969). Ao término desse período, embora tivesse sido convidado a permanecer nos Estados Unidos na condição de professor e pesquisador, retornou ao Brasil: "Eu vim convidado para iniciar a pós-graduação da Físico-Química da USP."

Entretanto, o salário inicial oferecido pela universidade para que o convite fosse aceito não correspondeu ao que havia sido previamente combinado, dando início a uma relação conflituosa entre ele e a USP, que se estendeu por toda a década seguinte. Segundo Eduardo Peixoto, apesar de muitas dificuldades, o laboratório e o grupo de pesquisa da pós-graduação em química quântica liderados por ele foram se desenvolvendo, consolidando e recebendo o reconhecimento externo. 
Mas publicamente assim numa reunião grande, eles [auditores internacionais] disseram claramente que o único grupo que realmente fazia pesquisa de alto nível no país era o meu. E aí criou um mal-estar muito chato porque todos eles disseram isso e aí comecei a achar os grandes inimigos.

Eduardo Peixoto não se pronunciou sobre quem seriam esses "grandes inimigos”. É possível que ele se referisse aos pesquisadores da USP - instituição que tinha em seu quadro funcional inúmeros cientistas e profissionais acentuadamente opositores ao regime militar - que estariam insatisfeitos com a reforma universitária de 1970. Essa reforma teria criado o Instituto de Química, englobando ali atividades desenvolvidas em vários outros departamentos, o que acarretaria na perda de prestígio, poder e recursos financeiros institucionais daqueles pesquisadores.

O término do convênio com o governo americano, que basicamente mantinha as atividades de pesquisa do grupo de Eduardo Peixoto dentro da USP, parece ter sido também um fator de contribuição para o encerramento das suas atividades ali.

\section{O personagem em nova cena: o governo federal}

Segundo Eduardo Peixoto, aquele grupo de pesquisa obteve o reconhecimento externo de sua capacidade técnica, sobretudo por parte de órgãos do governo federal, como a Coordenação de Aperfeiçoamento de Pessoal de Nível Superior (Capes), e do Banco Nacional de Desenvolvimento Econômico (BNDE). Portanto, é bastante plausível pensar que todos estes fatos, aliados às suas antigas relações pessoais com importantes figuras do cenário político baiano, tenham contribuído para que Eduardo Peixoto aceitasse o convite formulado por Luiz Antonio Sande de Oliveira (1933-1995), que havia sido secretário de Fazenda do Estado da Bahia entre 1971 e 1973, e era o então presidente do BNDE àquela época (1979) para que ele ocupasse o cargo de assessor da presidência daquela instituição.

Aí fiquei como assessor, era um departamento chamado Cotep, Consultoria Técnica da Presidência, que assessorava o presidente em todas as matérias do banco. Isso foi evoluindo e meses depois finalmente ele foi transformado em superintendência, e aí eu virei superintendente do banco, da 
presidência. Eu fui o primeiro superintendente técnico da presidência do BNDE.

Portanto, o ingresso no BNDE, em 1979, teria sido o passo inicial de seu afastamento das pesquisas laboratoriais acadêmicas, e essa "assessoria em todas as matérias do Banco" teria permitido o seu envolvimento com o setor público, inclusive com o Ministério da Saúde.

\section{O Castelo Mourisco: ${ }^{1}$ nova cena e outro personagem para o ator}

Naquele ano de 1979, quando já estava em curso a distensão do governo militar e quando as pressões sociais se acentuaram, sobretudo no que se refere à política de saúde, Antônio Delfim Neto, economista de presença marcante e de forte influência nos governos militares anteriores àquele do general Figueiredo (1979-1985), à frente da pasta do Ministério do Planejamento, ampliou o âmbito de atuação do BNDE para os projetos sociais, aí incluídas as áreas da saúde, educação e cultura. Essa parece ter sido a forma de aproximação entre Eduardo Peixoto e a Saúde:

Então eu me aproximei da Saúde, pra saber as necessidades da Saúde, pra botar o banco lá. E aí eu percebi que a Saúde estava em petição de miséria. Foi quando chegou o ministro Arcoverde. E a Fiocruz também. Todo mundo sem dinheiro.

Essa aproximação de Eduardo Peixoto com a Saúde parecia se encaixar perfeitamente às aspirações de renovação dos quadros funcionais e das diretrizes políticas que o ministro Waldyr Arcoverde queria dar à sua gestão. Segundo o então secretário-geral do Ministério da Saúde, o médico Mozart de Abreu Lima (2003, p. 747), responsável por importantes mudanças estratégicas do Plano Nacional de Imunizações (PNI):

1 Referência ao Pavilhão Mourisco, prédio central da Fundação Oswaldo Cruz. 
A nossa ida para o ministério visava adotar os ares da abertura política, de consultar instituições da sociedade, de buscar elementos, na sociedade, para compor equipes, elementos que vinham com outras informações e outras experiências, diferentes daquelas do núcleo segmentado que tradicionalmente atuava no ministério.

Estas duas últimas declarações indicam o que teria sido o primeiro contato de Eduardo Peixoto com a Fundação Oswaldo Cruz e os motivos para que, em 1979, fosse formulado o convite de seu presidente, Guilardo Martins Alves, para que assumisse a vice-presidência de desenvolvimento tecnológico (VPDT) da Fiocruz, concomitantemente às suas atividades de assessoria no BNDES.

Eu entrei como vice-presidente. Só que a Fiocruz era dividida na área de ensino, na área de pesquisa e na área de todo o resto. E todo o resto era a vice-presidência de Desenvolvimento Tecnológico. E isso pegava Biomanguinhos [Instituto de Tecnologia em Imunobiológicos], toda a parte de vacinas, Farmanguinhos [Instituto de Tecnologia em Fármacos], o INCQS que surgiu, toda a parte de... todos os hemocentros e o que era mais? E o Centro de Informações Toxicológicas. Era bem grande!

Com a decisão da transferência do LCCDMA para a Fiocruz já tomada e promulgada legalmente, Eduardo Peixoto, sendo assessor técnico da presidência do BNDES e externo aos quadros do Ministério da Saúde, parecia reunir os requisitos necessários para assumir a responsabilidade inicial de viabilizar e concretizar a referida transferência. No entanto, a execução dessa transferência envolvia recursos humanos e financeiros cujos processos de aplicação não tinham diretrizes nem responsabilidades claramente definidas, inclusive quanto à participação de organismos internacionais, como a Organização Pan-Americana de Saúde (Opas).

A Opas estava botando o dinheiro todo aqui [em São Paulo]. E aí quando eu entrei estava essa confusão grande. Com o prédio parado lá da Fiocruz... O do INCQS. Já tinha o esqueleto do prédio. Já tinha o esqueleto lá parado e não se sabia bem o que fazer com aquilo. Bom, seria mais um prédio da Fiocruz, mas que não estava muito bem definido o que seria. Seria na concepção da Opas um laboratório de alguns testes. Tinha uma ideia de controle de qualidade, mas uma parte dele ia ser feito aqui no [Instituto] 
Adolfo Lutz aqui [São Paulo]. Num prédio aqui. Os equipamentos já estavam até aqui. Então estava tudo, mas muito confuso está entendendo? Tinha muita gente dando palpite, muitos assessores da Opas...

Nesse contexto decisório, segundo ele, absolutamente caótico, e tendo o respaldo na delegação de poder que lhe haviam confiado o Ministro da Saúde e o presidente da Fiocruz, Eduardo Peixoto teria tomado a decisão de transferir as verbas para a fundação, de minimizar a participação do organismo internacional e de estabelecer as diretrizes da vice-presidência que assumira. Assim, ao declarar: "Vamos modernizar Biomanguinhos, vamos botar um Farmanguinhos decente e vamos fazer um centro de controle de qualidade para o país inteiro se orgulhar", é possível observar a determinação de Eduardo Peixoto, acentuadamente na questão relativa à resolução dos problemas que àquele momento o Ministério da Saúde enfrentava frente aos programas de vacinação no país, sobretudo no que se refere ao controle da poliomielite.

$\mathrm{Ou}$ seja, Eduardo Peixoto teria então percebido que a um problema conjuntural de tal ordem se impunha uma reestruturação institucional à altura. Assim, a partir de 1980, um novo plano de ação foi implementado após a irrupção de epidemias ocorridas nos estados do Paraná e Santa Catarina.

Em 1981, de acordo com Schatzmayer et al. (2002), os governos do Brasil e do Japão firmaram acordo de cooperação técnica com o objetivo de transferir tecnologia de produção de vacina contra a poliomielite e o sarampo, ficando a cargo do INCQS, então recém-inaugurado, o seu controle de qualidade.

Portanto, para Eduardo Peixoto, a qualidade da vacina era o foco da questão:

$\mathrm{Na}$ minha visão era exatamente isso, porque eu tinha a concepção que era um problema de qualidade. Mas o governo não estava interessado nisso $\mathrm{O}$ governo estava interessado no INCQS como um controle ali de, controle das coisas, mas não era, não tinha essa noção de que a qualidade era fundamental. Eu marquei um objetivo. O objetivo vai ser esse e é lá que nós vamos crescer... [o controle de qualidade voltado] para os problemas sociais graves. E o principal era a vacina. Nada disso saía em papel, nada disso era exposto.

Percebemos, portanto, que as outras atribuições anteriores do LCCDMA - controle da qualidade de alimentos, medicamentos, saneantes e 
cosméticos - não se constituiriam como a prioridade de sua gestão, e esse posicionamento era compartilhado com o secretário-geral do Ministério da Saúde, que sobre a extinção daquele órgão e a criação do INCQS afirmava:

[O LCCDMA] era um órgão burocrático. Recebia amostras, analisava, selava, lacrava. Aí o cara se defendia, abria outra amostra. Era um órgão que não tinha capacidade de induzir [...] Nós precisávamos de estruturas capazes de aperfeiçoar o controle em pleno vôo, porque senão a gente não tinha vacina. Nós queríamos entrar nas empresas com outra visão. Era a Instituição que entrava para corrigir métodos e aperfeiçoar a qualidade. (Lima, 2003, p.759).

A questão que se apresenta é se apenas essa determinação de Eduardo Peixoto e o apoio político do Ministério da Saúde teriam sido suficientes para viabilizar e concretizar a transferência e iniciar uma nova fase na política de controle de qualidade. Segundo Eduardo Peixoto, um fato determinante deu impulso às novas atividades do INCQS em áreas onde o LCCDMA não atuava efetivamente, passando, a partir de então, a serem definidos os objetivos e o compromisso social da instituição recém-inaugurada: a suspensão da campanha de vacinação contra a poliomielite, às vésperas de sua realização, proposta por ele ao ministro da Saúde, devido à comprovação da ineficácia da vacina a ser aplicada.

A descoberta da contaminação nos lotes da vacina a serem empregados em uma campanha de governo [...] certamente influiu para que os recursos anteriormente contratados fossem logo repassados à Fiocruz para a conclusão das obras [no INCQS], para a aquisição de equipamentos e materiais, assim como para a contratação e o treinamento de pessoal necessário ao início das atividades do novo instituto. (Ponte, 2003, p. 640).

Mais do que isso, para Eduardo Peixoto, tal ação também teria resgatado a credibilidade e respeitabilidade da própria Fundação Oswaldo Cruz, possibilitando o aporte de novos recursos financeiros:

O fato é que com a simples ação do INCQS na pólio, essa simples ação trouxe uma força tão grande para a fundação, tão grande, que abriu o financiamento para Farmanguinhos, abriu todos os recursos que foram para 
Biomanguinhos, abriu para área de hemocentros, abriu para a área toxicológica, abriu para pesquisa, abriu para saúde pública, abriu para todo mundo.

Se a ação do INCQS parecia ter sido bem frutífera para a Fiocruz, resta saber como isso se projetava para a relação com a outra parceria esperada, isto é, com a Secretaria Nacional de Vigilância Sanitária. Segundo Eduardo Peixoto, era uma "relação turbulentíssima", visto que "a Vigilância basicamente queria todo o controle de qualidade. E eu era radicalmente contra. Eu disse que não. Que a Vigilância tinha que trabalhar com o controle de qualidade.”

Essas "relações turbulentíssimas" tinham origem tanto nas questões que envolviam as análises realizadas pelo INCQS quanto na disposição de verbas da Opas. Segundo Eduardo Peixoto,

A Vigilância Sanitária queria toda a verba da Opas para ela. E na realidade houve um problema lá prático, que ia ser transferida toda para a Vigilância Sanitária e terminou voltando tudo para a Fiocruz, como era para ser mesmo. E aí criou outro problema grande com a Vigilância Sanitária que, e com o ministério, mas que com o passar do tempo foi se transformando e as pessoas todas começaram a perceber que a gente queria trabalhar assim, para o país E eles também queriam, então no final, eu acho que foi uma grande festa, porque o Ministério da Saúde ficou muito contente, a Vigilância Sanitária encontrou apoio...

Este "contentamento" e apoio ao INCQS por parte do governo podem ser observados pelas declarações do então secretário-geral do Ministério da Saúde:

O INCQS se manteve porque quando vieram as pressões, o secretário-geral disse assim: o INCQS vai continuar e pra mudar isso, vocês têm passar por cima de mim. Só me tirando do ministério ou me matando. O INCQS é um objetivo meu, particular, que será mantido a ferro e a fogo. Nós apostamos nessa idéia e estamos trabalhando pra que ele seja o melhor. (Lima, 2003, p. 763).

Estas últimas declarações parecem indicar que as decisões e encaminhamentos relativos à vigilância sanitária e ao controle de qualidade de produtos poderiam estar dissociados de uma política governamental, definida e 
estabelecida, sendo centrados nas proposições do superintendente do instituto e nas determinações pessoais do secretário-geral do Ministério da Saúde.

Do mesmo modo, a aplicação de recursos financeiros na compra de equipamentos corroboraria a inexistência de política governamental definida. No entanto, na visão de Eduardo Peixoto, a aplicação de recursos financeiros na compra de equipamentos que poderia parecer, à primeira vista, uma irresponsabilidade, permitia uma flexibilidade de ação do poder público:

Por exemplo, os grandes equipamentos que a gente precisava eram equipamentos que foram financiados pelo governo sem nenhum projeto, a maioria deles. Porque o ministro pessoalmente dizia: "Não. Faça e depois manda o projeto." Mas depois a gente chamava ele e dizia:"Aqui, aqui está o projeto, venha ver o equipamento [...]". Ia [lá] ver funcionando e ia embora e via o resultado. E a gente dizia: "Olhe, com isso a gente fez isso, isso, isso e isso para o país."

A vinculação entre as atividades desenvolvidas pela instituição e os interesses da sociedade, portanto, nos parece se estabelecer, mais uma vez, por uma avaliação pessoal e intuitiva.

Por fim, no que diz respeito aos recursos humanos, vale ressaltar que no momento da transferência do LCCDMA para a Fiocruz, a maioria dos servidores ali lotados estava em época de aposentadoria. Dessa forma, além de alguns doutores e doutorandos oriundos de universidades do Rio de Janeiro, convidados a formar basicamente o grupo de direção da instituição, Eduardo Peixoto montou sua equipe a partir da contratação de profissionais recém-graduados.

Pro INCQS a gente trouxe alguém, alguns do LCCDMA. O resto eram todos novos. Aí eu contratei a equipe toda. Bom, tinha que ser jovem. Jovem e querer trabalhar. Eu fui fazendo uma seleção pessoalmente e contratando as pessoas. Com a finalidade que eu queria. Químicos, microbiologistas, pessoal para trabalhar no biotério e assim por diante.

Com isso, o INCQS foi oficialmente inaugurado em 4 de setembro de 1981, dando início às suas atividades, sob a direção de Eduardo Motta Alves Peixoto. 


\section{Os personagens, o ator e o autor}

O itinerário da vida profissional de Eduardo Peixoto se inscreve na continuação de sua linhagem paterna. Ainda bem jovem, o interesse que demonstrou pela química o conduziu ao trabalho e às consultorias nas empresas privadas, até chegar à carreira universitária. Ao optar pela direção de uma instituição pública voltada para as atividades de vigilância sanitária, buscou pôr em prática não somente suas qualidades de pesquisador, mas também as de gerência administrativa.

Se por um lado, pelas memórias de Eduardo Peixoto pode-se considerar que o dirigente teria dado os fundamentos para que a instituição fosse igualmente capaz de atender às exigências emergentes tanto da política de desenvolvimento tecnológico do país quanto da sociedade, por outro, o INCQS pode ser visto como o resultado das necessidades técnico-científicas imperativas da política governamental na área da saúde ao longo da década de 1970, as quais foram perfeitamente ajustadas ao perfil profissional de seu primeiro dirigente.

O personagem permaneceu no cenário até 1985. Nesse ano, após os 21 anos da vigência do regime militar no país, as luzes da democracia começaram a se acender na ribalta, exigindo a presença e a atuação de novos atores e de novo direcionamento para a instituição, para alinhar-se, então, aos anseios da sociedade brasileira no tocante ao controle de qualidade da saúde de seus cidadãos.

Isto, porém, é o enredo de outra peça.

Por ora, se cerra esta cortina.

\section{Referências}

BRASIL. Lei no 1.920 de 23 de julho de 1953. Cria o Ministério da Saúde e dá outras providências. Rio de Janeiro, 1953. Disponível em: <http://www6.senado.gov.br/ legislacao/ListaTextoIntegral.action?id=82528>. Acesso em: 15 jun. 2010.

. Lei no 2.187, de 16 de fevereiro de 1954. Cria o Laboratório Central de Contrôle de Drogas e Medicamentos, e dá outras providências. Rio de Janeiro, 1954. Disponível em: $<$ http://www6.senado.gov.br/legislacao/ListaTextoIntegral.action?id=83019>. Acesso em: 15 jun. 2010. 
BRASIL. Decreto $n^{\circ}$ 49.974-A, de 21 de janeiro de 1961. Regulamenta, sob a denominação de Código Nacional de Saúde, a Lei no 2.312, de 3 de setembro de 1954, de "Normas Gerais Sôbre Defesa e Proteção da Saúde”. Brasília, 1961. Disponível em: <http://www6.senado. gov.br/legislacao/ListaTextoIntegral.action?id=160292>. Acesso em: 15 jun. 2010.

. Decreto $n^{\circ}$ 79.056, de 30 de dezembro de 1976. Dispõe sobre a organização do Ministério da Saúde e dá outras providências. Brasília, 1976. Disponível em: <http:// www2.camara.gov.br/legin/fed/decret/1970-1979/decreto-79056-30-dezembro-1976428077-publicacaooriginal-1-pe.html>. Acesso em: 15 jun. 2010.

. Ministério da Saúde. Portaria $n^{\circ}$ 469, de 13 de outubro de 1978. Brasília, 1978. Disponível em: <http://www.incqs.fiocruz.br/images/stories/incqs/legislacao/ portaria-469-13_10_1978.pdf>. Acesso em: 15 jun. 2010.

Lei no 8.080, de 19 de setembro de 1990. Dispõe sobre as condições para a promoção, proteção e recuperação da saúde, a organização e o funcionamento dos serviços correspondentes e dá outras providências. Brasília, 1990. Disponível em: <http://www. planalto.gov.br/ccivil_03/Leis/L8080.htm>. Acesso em: 15 jun. 2010.

BIRCHAL, S. O. Empresa e indústria alimentícia no Brasil. Revista de Administração da FEAD-Minas, v. 1, n. 2, p. 55-70, jul./dez. 2004.

COSTA, E. A. Vigilância sanitária: proteção e defesa da saúde. São Paulo: Hucitec: Sociedade Brasileira de Vigilância de Medicamentos, 1999.

DREIFUS, R. A. 1964: a conquista do Estado: ação política, poder e golpe de classe. 6. ed. Petrópolis: Vozes, 2006.

HAMILTON, W.; AZEVEDO, N. Um estranho no ninho: memórias de um ex-presidente da Fiocruz. História, Ciências e Saúde - Manguinhos, v. 8, n. 1, p. 237-264, mar./jun. 2001.

LIMA, M. A. A saúde entre o Estado e a sociedade. Entrevista concedida a Carlos Fidelis Ponte. História, Ciências e Saúde - Manguinhos, v. 10, sup. 2, p. 743-770, 2003.

PONTE, C. F. Vacinação, controle de qualidade e produção de vacinas no Brasil a partir de 1960. História, Ciências e Saúde - Manguinhos, v. 10, sup. 2, p. 619-653, 2003.

RISI Jr., J. B. A produção de vacinas é estratégica para o Brasil. Entrevista concedida a Carlos Fidelis Ponte. História, Ciências e Saúde - Manguinhos, v. 10, sup. 2, p. 771-783, 2003.

SCHATZMAYER, H. G et al. Erradicação da poliomielite no Brasil: contribuição da Fundação Oswaldo Cruz. História, Ciências e Saúde - Manguinhos, v. 9, n. 1, p. 11-24, jan./ abr. 2002. 
Resumo: O Instituto Nacional de Controle de Qualidade em Saúde é uma das unidades técnicocientíficas da Fundação Oswaldo Cruz. Suas atividades estão intrinsecamente vinculadas às ações de vigilância sanitária. Tendo sido inaugurado em 1981, e muito embora sua atuação tenha sido e ainda seja de reconhecida relevância no âmbito da saúde coletiva, a instituição não se tornou objeto de estudos acadêmicos até o presente momento. Na elaboração do presente trabalho, servimo-nos dos depoimentos orais de seu primeiro dirigente, Eduardo Motta Alves Peixoto, visando a apresentação da configuração que teria sido dada ao início da trajetória institucional, incorporando-se alguns outros testemunhos prestados por personalidades atuantes na esfera governamental da Saúde no início da década de 1980. A inserção de Eduardo Peixoto na Fundação Oswaldo Cruz se deu ao final de 1979, como vice-presidente de Desenvolvimento Tecnológico, cargo que ocupou concomitantemente ao de diretor do INCQS até 1985.

Palavras-chave: controle de qualidade, vigilância sanitária, INCQS.

Characters meeting an author: the actor-director of $\mathbf{a ~}^{\text {th }}$ century scientific institution in Brazil

\begin{abstract}
The National Institute of Quality Control in Health (INCQS) is one of the technical-scientific departments of Fundação Oswaldo Cruz. Its activities are inextricably linked to the National Health and Safety actions. The Institute premises were inaugurated in 1981 and, although its role has been extremely relevant to Health and Safety system, so far the Institute has not been the object of any academic research. In this present research, the focus is on oral reports from the Institute's first director, Eduardo Motta Alves Peixoto, in order to present the initial organization of the Institution's History, incorporating other reports given by important names from the Health System in the beginning of the 1980s. Eduardo Peixoto started working in Fundação Oswaldo Cruz in the end of 1979, as Vice-president of Technological Development department, a position that he was in charge of simultaneously as the director of INCQS until 1985.
\end{abstract}

Keywords: quality control, Health and Safety System, INCQS.

Recebido em 10/07/2010

Aprovado em 25/10/2010 